\title{
P106: Towards a new methodology in hygienic handrub testing
}

\author{
M Wilkinson ${ }^{1}$, DR Macinga ${ }^{2,3^{*}}$, C Bradley $^{1}$, J Arbogast $^{3}$, B Okeke $^{3}$, F Brill $^{4}$, A Fraise $^{1}$ \\ From 2nd International Conference on Prevention and Infection Control (ICPIC 2013) \\ Geneva, Switzerland. 25-28 June 2013
}

\section{Introduction}

Internationally-recognized standards for evaluating alcohol based hand rubs (ABHR) differ significantly in methodology and success criteria. Hand hygiene authorities including the WHO and U.S. CDC have recognized inherent weaknesses with the current methods and have highlighted the need for improved in vivo efficacy methods, which reflect the use conditions and experience of healthcare practitioners.

\section{Methods}

Variables within the European Standard EN1500 (Hygienic Handrub) method and ASTM standard E2755-10 method, including methods of hand contamination and modes of recovery, were tested on their ability to provide a consistent, robust method for testing ABHR.

\section{Results}

The EN1500 method of contamination did not allow for hands to be sufficiently dry to adequately test smaller volumes of ABHR, typical of healthcare practitioner use. Whilst the ASTM E2755 method did allow for the hands to be sufficiently dry, the 'glove-juice' sampling technique of recovery was more cumbersome and led to a higher limit of detection, and thus potentially poor discrimination between products $(2 \times 3 \mathrm{ml}$ of $60 \% \mathrm{v} / \mathrm{v}$ propan-2-ol gave a mean $\log _{10}$ RF of 3.65 ; standard deviation 0.472). A hybrid method consisting of the ASTM E2755 method of contamination with an EN1500 method of recovery resulted in baseline recoveries of Escherichia coli $\mathrm{K} 12$ that were relatively low (mean $\log _{10}$ precount of 5.57; standard deviation 0.615). A hybrid method comprising the contamination of fingerpads with small volumes of microbial broth, coupled with the EN1500 method of recovery, appeared to yield a robust method that allowed dry hands to be tested with ABHR, with a low limit of detection $(2 \times 3 \mathrm{ml}$ of $60 \% \mathrm{v} / \mathrm{v}$ propan-2-ol gave a mean $\log _{10}$ RF of 5.62; standard deviation 1.108).

\section{Conclusion}

Whilst further work is needed, it appears that a method involving the contamination of fingerpads, followed by the EN1500 method of recovery, may be a suitable candidate for inclusion in a single, globally-recognized in vivo efficacy standard, which would be more predictive of ABHR performance under clinical use conditions.

\section{Disclosure of interest}

None declared.

\section{Author details}

'University Hospitals Birmingham NHS Foundation Trust, Birmingham, UK. ${ }^{2}$ Northeast Ohio Medical University, Rootstown, OH, USA. ${ }^{3} \mathrm{GOJO}$ Industries, Inc., Akron, OH, USA. ${ }^{4}$ Dr. Brill + Partner GmbH, Hamburg, Germany.

Published: 20 June 2013

\section{doi:10.1186/2047-2994-2-S1-P106}

Cite this article as: Wilkinson et al:: P106: Towards a new methodology in hygienic handrub testing. Antimicrobial Resistance and Infection Control 2013 2(Suppl 1):P106.

${ }^{2}$ Northeast Ohio Medical University, Rootstown, OH, USA

Full list of author information is available at the end of the article 